\title{
COMPARATIVE STUDY BETWEEN INCISION \& DRAINAGE AND SONO-GUIDED ASPIRATION FOR THE MANAGEMENT OF DEEP-SEATED BREAST ABSCESS
}

\author{
Ajay Kumar Thakral1, Divya Prasad ${ }^{2}$
}

${ }_{1}^{1}$ Associate Professor, Department of General Surgery, Hamdard Institute of Medical Sciences and Research, New Delhi, India. ${ }^{2}$ Assistant Professor, Department of General Surgery, Hamdard Institute of Medical Sciences and Research, New Delhi, India.

\begin{tabular}{l}
\hline ABSTRACT \\
BACKGROUND \\
Breast abscess is a disease more of a lactating mother. Traditionally breast abscess was treated with incision and drainage which \\
was more invasive and really painful for lactating mother. With the availability of antibiotics more conservative approach came into \\
practice. Aspiration of deep-seated breast abscess, a less invasive procedure, has shown promising results in many studies. \\
The aim of this study was to compare cosmetic results, recovery times, milk discharge, pain relief and recurrence rates in the \\
management of deep-seated breast abscess with aspiration and Incision \& Drainage.
\end{tabular}

\section{MATERIALS AND METHODS}

This non-randomised controlled trial study was performed at department of surgery, HIMSR, Jamia Hamdard, New Delhi from September 2016 to September 2018. Patients were divided into two groups. In group A, aspiration was done under sonographic guidance. In group B Incision and drainage was done. 68 patients were treated, out of which 42 patients were treated in group A and 26 patients was treated in group B. Follow up of patients was done on regular basis for 6 months (Twice a week for one month, twice a month for 2 months than every month for 3 months).

\section{RESULTS}

A total of 68 patients were included in the study. $88.2 \%$ patients were lactating mothers and $11.2 \%$ patients were non-lactating. Out of 68 patients 42 were treated in group A and 26 were treated in group B. In group A none had suffered from mammary fistula. In group B 7.6\% patients had mammary fistula. In group A $11.9 \%$ patients had scar marks that too because of conversion to incision and drainage procedure. In group B 100\% patients had scar mark. In group A 28 patients were almost pain free after 2 wks. In group B 26 patients were almost pain free after 4 weeks.

\section{CONCLUSION}

Aspiration under sonographic guidance is better mode of management than incision and drainage in deep seated breast abscess.

\section{KEY WORDS}

Breast Abscess, Incision \& Drainage, Aspiration.

HOW TO CITE THIS ARTICLE: Thakral AK, Prasad D. Comparative study between incision \& drainage and sono-guided aspiration for the management of deep-seated breast abscess. J. Evolution Med. Dent. Sci. 2018;7(50):5343-5346, DOI: $10.14260 /$ jemds/2018/1183

\section{BACKGROUND}

Breast abscess is a painful lump in breast tissue. ${ }^{1}$ This is one of the serious breast-feeding problems but is also not very common, occurring in only $3 \%$ of all breast-feeding mothers that develops as mastitis and or recurrent plugged duct conditions. Lactational mastitis is most commonly caused by staphylococcus aureus as $50 \%$ of infants harbour these bacteria in the nasopharynx. ${ }^{2}$ Non lactational breast abscess is more common in obese patients and smokers than in general population. During the cellulitis phase, treatment with antibiotics may be expected to give rapid resolution. The traditional management of breast abscess involves incision and drainage of pus along with anti-staphylococcal antibiotics, but this is associated with prolonged healing time,

'Financial or Other Competing Interest': None.

Submission 25-10-2018, Peer Review 27-11-2018,

Acceptance 03-12-2018, Published 10-12-2018.

Corresponding Author:

Dr. Ajay Kumar Thakral,

Associate Professor, Department of General Surgery,

Hamdard Institute of Medical Sciences and Research,

New Delhi, India.

E-mail: ajayshweta22@yahoo.co.in

DOI: $10.14260 /$ jemds $/ 2018 / 1183$ regular dressings, difficulty in breast feeding and possibility of milk fistula and unsatisfactory cosmetic outcome. ${ }^{3}$ It has recently been reported that breast abscess can also be treated by needle aspiration.

\section{Objectives}

To compare cosmetic result, recovery time, milk discharge, pain relief and recurrence rate in the management of deepseated breast abscess with aspiration and Incision \& Drainage.

\section{MATERIALS AND METHODS}

This non-randomised controlled trial study was carried out at department of surgery, HIMSR, Jamia Hamdard, New Delhi from September 2016 to September 2018. Patients with clinical diagnosis of breast abscess and not treated before for the same were included in the study. Diagnosis of breast abscess was based on clinical history, examination and ultrasound breast. 68 patients were treated non-randomly out of which 42 patients were treated in group $A$ and 26 patients were treated in group B. The sample size of 68 patients were taken for convenience. All patients were informed and explained about the disease and treatment options available. Patient consent was taken before opting treatment plan and were accordingly put into respective groups. Patients were treated in two groups. In group $\mathrm{A}$, aspiration under 
sonographic guidance was done. In group B, incision and drainage was done.

In group A abscess was located with help of ultrasound and under standard aseptic precautions overlying skin was infiltrated with $2 \%$ xylocaine using $26 \mathrm{G}$ needle and then aspiration was done using $18 \mathrm{G}$ spinal needle. After aspiration the area was cleaned, and compression dressing was applied. Follow-up ultrasound examination was done in all cases. USGguided aspiration was repeated on the 7 th day if required and again follow-up was done on the 14th day. At every follow-up, a clinical assessment with USG was done to assess complete resolution of the abscess. If the abscess persisted even after three aspirations, it was considered as treatment failure and hence incision and drainage was advised. Patients who underwent aspiration under ultrasonic guidance were treated on outpatient basis. Success of aspiration was evident immediately during the scan following which patients were mostly discharged home with the advice to return for follow up for a repeat scan after one week.

In group B patients were admitted and routinely prepared for general anaesthesia. All the incision and drainage procedures were done under general anaesthesia after full informed consent. Post-operative care included IV antibiotics for a period of 3 days to a week depending on the patient condition and antibiotics were tailored to the culture and sensitivity results. Dressing were changed daily starting from post-operative day 1 which included thorough irrigation of the abscess cavity and gentle packing to keep the mouth of abscess cavity open till expectant healing from the base of the cavity.
This process continued for a period of one week or more till full healing was achieved.

In both groups pus was sent for culture and sensitivity. In patients where culture and sensitivity were inconclusive triple regime antibiotics therapy amoxicillin with clavulanic acid, amikacin and metrogyl was given for 7 to 10 days. In both groups breast feeding was continued from the normal breast and milk expulsion was advised from the diseased breast.

\section{Exclusion Criteria}

Large abscess more than $10 \mathrm{cms}$. in diameter, superficial abscess with gross involvement of skin, about to rupture abscesses were excluded from the study.

\section{Statistical Analysis}

Data was analysed using SPSS software. Percentage, Mean, and Standard Deviation of resolution time and wound healing time of both groups were calculated. Results of two treatment groups were compared using chi square test to access the hypothesis and a p value of $<0.05$ was taken as statistically significant.

\section{RESULTS}

A total of 68 patients were included in the study. 60(88.2\%) patients were lactating mothers and $8(11.8 \%)$ patients were non-lactating. The mean age was 27.19 yrs. (Range 18-38, SD 5.2644)

Out of 68 patients 42 were treated in group A and 26 were treated in group B.

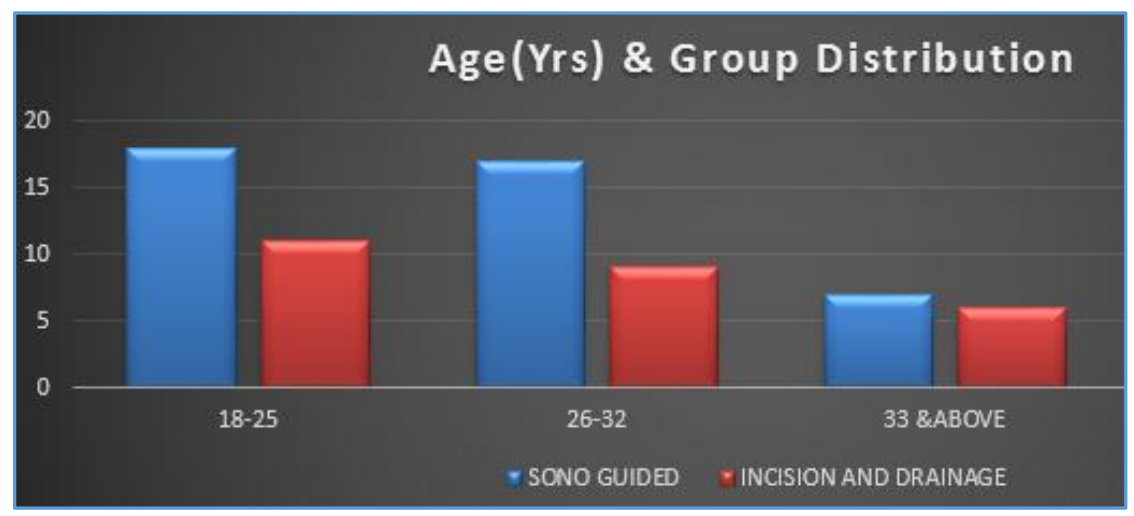

Swelling and pain were the common presentation in all the subjects. While allied complaints synchronous with swelling and pain was fever in 57 patients, redness of overlying skin was in 9 patients and apprehension of tumor was in 37 patients.

In group A out of 42 patients 9 patients required repeated aspirations and 5 patients required Incision and Drainage because of recollection and ischaemic changes in overlying skin.

\begin{tabular}{|c|c|c|c|c|}
\hline $\begin{array}{c}\text { Cured in } \\
\text { Single } \\
\text { Aspiration }\end{array}$ & $\begin{array}{c}\text { Cured in } \\
\text { Two } \\
\text { Aspirations }\end{array}$ & $\begin{array}{c}\text { Cured in } \\
\text { Three } \\
\text { Aspirations }\end{array}$ & $\begin{array}{c}\text { Total Cured } \\
\text { with } \\
\text { Aspirations } \\
\text { only }\end{array}$ & $\begin{array}{c}\text { Converted to } \\
\text { Incision \& } \\
\text { Drainage }\end{array}$ \\
\hline $28(66.6 \%)$ & $6(14.2 \%)$ & $3(7.1 \%)$ & $37(88 \%)$ & $5(11.9 \%)$ \\
\hline
\end{tabular}

$\mathrm{P}<0.015$.
In group B out of 26 patients 24 patients had their wounds healed in around 3 wks. In 2 patients wounds had to be debrided again and they had taken around 5 wks. to get healed.

In group A 5 (11.9\%) patients had delayed recovery in comparison to group B 2 (7.9\%) had delayed recovery.

\begin{tabular}{|l|c|c|}
\hline Delayed Recovery & Group A (42) & Group B (26) \\
\hline No. of Patients (\%) & $5(11.9 \%)$ & $2(7.6 \%)$ \\
\hline $\mathrm{P}<0.024$.
\end{tabular}

In group A none had suffered from mammary fistula. In group B two patients had mammary fistula

\begin{tabular}{|c|c|c|}
\hline Mammary Fistula & Group A (42) & Group (26) \\
\hline No. of Patients (\%) & Nil & $2(7.6 \%)$ \\
\hline
\end{tabular}




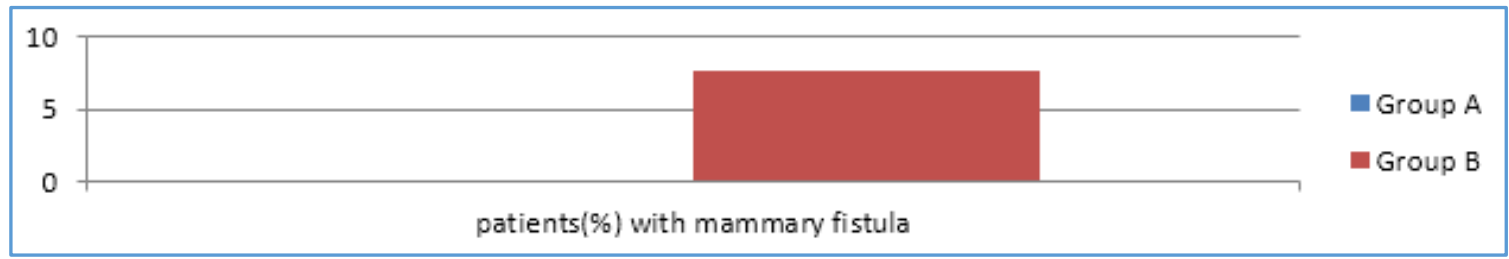

In group A, out of 42 patients only 5 patients have scar marks that too because of conversion to incision and drainage procedure. In group B all 26 patients have scar mark.

\begin{tabular}{|c|c|c|}
\hline & Group A (42) & Group B (26) \\
\hline Scar & $5(11.9 \%)$ & $26(100 \%)$ \\
\hline No Scar & $37(88 \%)$ & \\
\hline
\end{tabular}

$\mathrm{P}<0.05$.

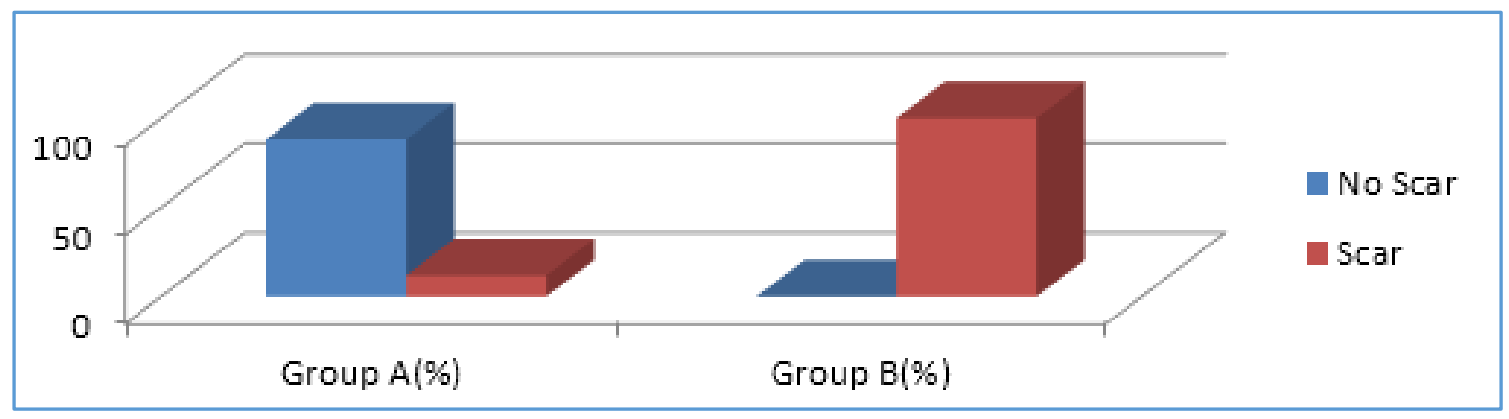

In group A, 28 patients were almost pain free after 2 wks. In group B 26 patients were almost pain free after 4 weeks. None of our patient either from group A or group B had shown recurrence of breast abscess.

\section{DISCUSSION}

Breast abscess has physical and psychological impact on patient as most of the time patient is a lactating mother. For long time breast abscess is being treated with incision and drainage which gives open wound and that is really troublesome for the lactating mother. ${ }^{4}$ In 1923 Battle and Bailey had first suggested about the possibility of aspiration as management of breast abscess. In our study we have compared the two groups according to treatment they have received. 5 In our study $88.2 \%$ were lactating mothers with breast abscess which are comparable with the findings in the series of Schwarz et al which had 83\% (Lactational) and 17\% (Non Lactational). Mean age of breast abscess in our study is 27.19 yrs. Ultrasound breast was done in all cases to locate site of breast abscess. ${ }^{6} 73 \%$ of the breast abscess were over upper outer quadrant of affected breast. One of the important aspect of this comparative analysis is post intervention mammary fistula formation. While there was none reported after aspiration under ultrasonic guidance, but we had observed in $7.6 \%$ cases of incision and drainage group, ${ }^{7}$ which resolved after giving tab cabergoline for milk suppression over a period of one week. This milk discharge from the wound was a source of considerable worry to the patient and added to the morbidity and cost. Scar mark on breast is major cosmetic issue which was $100 \%$ in group B and only in $11.9 \%$ cases of group $A$, that too because of conversion to incision and drainage. ${ }^{8}$ Similar outcome was observed in study done by Rajiv Karvdande et al which shows conversion rate of $13.3 \%$. Group A patients were pain free at least two weeks earlier than group B. Significant differences in the cost of the treatment were also noticed which included the cost of admission and the cost of surgery under general anaesthesia. Also adding to the cost of treatment in this group were the use of parenteral antibiotics and daily antiseptic dressings.

Considering the considerable and significant differences in the outcome of the two modalities which include pain relief, cosmetic results, recovery and recurrence we find aspiration to be far more suitable in selected cases of breast abscess.

\section{CONCLUSION}

Aspiration under sonographic guidance is better mode of management than incision and drainage in deep seated breast abscess.

\section{REFERENCES}

[1] Amir LH, Forster D, McLachlan H, et al. Incidence of breast abscess in lactating women: report from an Australian cohort. BJOG 2004;111(12):1378-81.

[2] Bharat A, Gao F, Aft RL, et al. Predictor of primary breast abscess and recurrence. World J Surg 2009;33(12):2582-6.

[3] Kamal K, Srivastava A, Dhar A. Management of lactational mastitis and breast abscess: review of current knowledge and practice. Indian J Surg 2013;75(6):430-5.

[4] Battle RJ, Bailey GN. The treatment of acute intramammary abscess by incision and aspiration. $\mathrm{Br} \mathrm{J}$ Surg 1923;10:436-41.

[5] Schwarz RJ, Shrestha R. Needle aspiration of breast abscess. Am J Surg 2001;182(2):117-9.

[6] Inch S. Mastitis: a literature review. World Health Organization, Division of Child Health and Development, Geneva. 1997. 


\section{Jemds.com}

[7] Yildirim AC, Bostanci H, Yildiz M. Postoperative milk fistula treated with cabergoline. Ankara Med J 2014;14(Ek 1):9-11.
Original Research Article

[8] Karvande R, Ahire M, Bhole M, et al. Comparison between aspiration and incision and drainage of breast abscess. Int Surg J 2016;3(4):1773-80. 